\title{
Scientifiques Sans Frontières Australia Providing Environmental Science Support to Local Communities in Rehabilitation of Waterways
}

\author{
Colin Scholes $\cdot$ Scott Mclean
}

Published online: 31 July 2008

(C) Springer Science + Business Media B.V. 2008

South-eastern Australia is currently experiencing one of the most severe droughts since European settlement (EPA Victoria 2007). The reduction in regional rainfall has stressed many waterways, as agricultural, industry and the environment compete for dwindling water resources. In response, governments, both regional and national, are taking action to improve the management of current water resources and planning for future needs. Examples of this response are the Australian federal government's MurrayDarling action plan. The importance of water resources and their management has also been recognised at a local community level, with the general populace displaying a growing interest in the condition of their local waterways. This is driven by a desire to improve their local environment, ensure waterways remain ecological viable and to achieve a form of community ownership of their waterway. One of the most important aspects of strong community involvement in any waterway management is the potential for strong consultation with local economies and industry for beneficial outcomes. Generally, clear signals of waterway degradation such as lack of aquatic fauna, rubbish accumulation, algal blooms and the presence of exotic flora, are easily recognised by vigilant

C. Scholes $(\bowtie) \cdot$ S. Mclean

Scientifiques Sans Frontières Australia, University of Melbourne,

PO Box 4237, Parkville, Victoria, 3052, Australia

e-mail: colinscholes@ssfaustralia.org communities, and the necessary efforts to rectify them undertaken. However, few groups have the necessary knowledge or experience in environmental science and water management to effectively address the underlying causes; such as water flow irregularities, erosion, along with agricultural and industry run-off, that if addressed can make a lasting beneficial change in the condition of the waterway.

Scientifiques Sans Frontières (SSF) Australia is a not-for-profit organisation that under its charter aims to transfer scientific knowledge into communities, to assist with their self-identified problems. This is part of SSF's overall mission to be the scientific link in the aid network of nongovernmental organisations. To achieve this aim, SSF Australia is currently assisting two local communities in the Greater Melbourne area. The projects' goals are twofold; initially monitor and audit their waterway and local environment, which will lead to rehabilitation plans aimed at having both river systems safe for active human recreation. The first project is focused on the Moonee Ponds creek, a tributary of the Yarra River, undertaken in partnership with the Moonee Ponds Creek Coordination Committee (MPCCC). The second project is along the Werribee river, in partnership with Waterkeepers Australia Ltd. (Fig. 1). Specifically, SSF Australia provides scientific monitoring of both waterways (and surrounding environments), including water-monitoring training to the local community with the goal of developing their environmental science literacy, as well as development of a waterway rehabilitation 
Fig. 1 Catchments of the greater Melbourne area, Australia

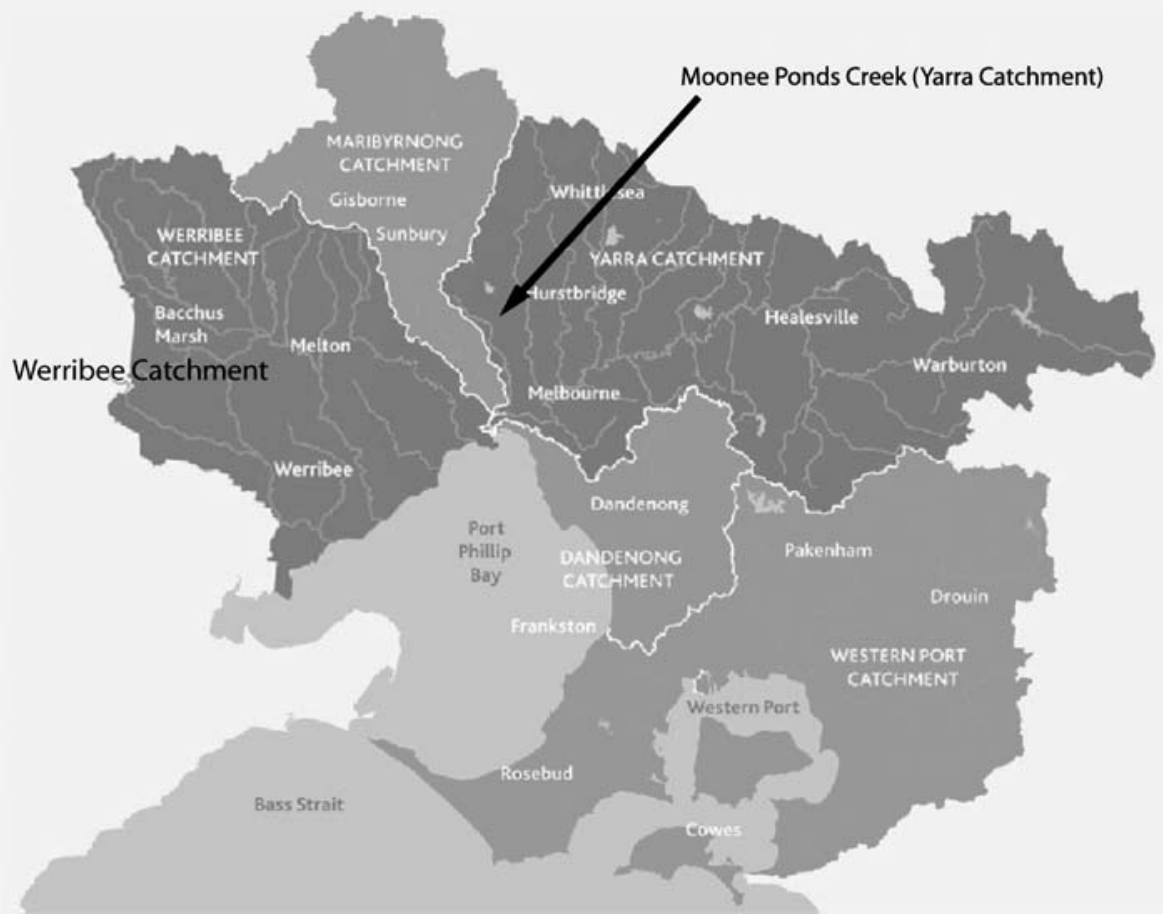

plan. As part of these programs, especially along the Moonee Ponds Creek, there is a large involvement of school students. The goal being to engage the students in environmental science; relating their studies in ecology and geology with their local landscape, human impact on the local environment and generating options to manage this impact. This allows them to make a positive contribution to their local environment and gain pride in their own community.

\section{Mile Creek, Moonee Ponds Creek}

The Moonee Ponds Creek derived its name from being a winding chain of waterholes, which during heavy rains swelled into a fast flowing temporary stream through what are now Melbourne's northwestern suburbs. Given the largely urbanised environment that has developed around it, the creek was considerably altered in the 1950s for flood protection and redirected for dock developments. This included the removal of bank vegetation, concrete lining of much of the lower reaches and connection to Melbourne's stormwater drain system. Subsequently, only the very upper reaches in rural parklands resemble its original state. The modifications to the creek have caused a dramatic decline in its ecological state, with Melbourne Water, the Victorian government's statutory water body, classifying its condition as very poor. Due to flood protection upstream and stormwater run-off entering the creek downstream water quality and flows are rated poor. The stability of the creek bed is, on the other hand, rated as good. However, the concreting of the lower reaches means vegetation and aquatic life are categorized as very poor (Melbourne Water 2007). In addition, past industries along the creek, such as foundries and tanneries, have left residual pollution in the creek bed. Given the significant urban area, the creek has a high social importance for passive recreation, with sections of the lower reaches undergoing some rehabilitation; this is part of the construction of a nearby toll road. Therefore, detailed water monitoring has been undertaken, with high readings observed for conductivity, phosphorus, Escherichia coli, copper, lead and zinc (Melbourne Water 2006).

The SSF Australia and MPCCC joint project has been focused on 5 Mile creek, a small tributary that joins the Moonee Ponds creek in Essendon. The creek is little more than a drain for the surrounding suburb that the MPCCC is in the process of rehabilitating. The long term goal is to restore the creek into a healthy water way in which swimming and other water 
recreation is possible. The rehabilitation time frame is 20 years and has the following stages:

- Initial creek clean-up and assessment: removal of rubbish and debris that has accumulated in the creek, along with appraisal of inflow sources and their potential to introduce pollution into the creek. Includes the installation of debris traps on these inflow sources.

- Revegetation and weed control: removal of invasive exotic flora from the creek bank and planting of native flora that matches as close as possible the pre-urbanisation state. This includes improvement of surrounding parklands for recreational activities.

- Creek bed rejuvenation: removal of the concrete lining in sections and converting the creek bed to a state which resembles its original condition; i.e. pools with a shallow stream connecting.

- Pollution prevention: locating all sources of potential pollution in the surrounding area and through consultation with the local community and the support of statutory authorities undertaking the necessary actions to minimise their impact on the creek system.

Over the course of this rehabilitation project water and soil monitoring will be undertaken to provide evidence of changes in the creek conditions, as well as locate sources of pollution and ensure any toxic residues within the creek bed are not disturbed.

\section{Werribee River}

The Werribee river catchment is the driest south of the Great Dividing Range in Victoria. This is because it lies in the rain shadow of the Otway ranges, and is mainly sourced by ephemeral streams. The catchment lies approximately $40 \mathrm{~km}$ south-west of Melbourne, and extends from the steep sided hills of the Great Dividing Range through the steeply incised Werribee gorge as it transverses the Rowsley Fault, onto flat plains before entering Port Phillip Bay. The lower reaches of the Werribee river pass through Melbourne Water's Western Treatment plant, and is an area of ecological significance because it provides habitat for large numbers of migratory wading birds. The majority of the catchment has been cleared for agricultural use since European settlement, mainly dryland grazing. There are two major irrigation districts, and therefore the catchment is now highly regulated with a number of diversions and weirs along the main channel and tributaries. In addition, pressure for low-cost housing means sizeable areas in the catchment have been set aside for residential growth, with current population over a quarter of a million and growing rapidly (ABS 2008). As a result, the natural flow regime of the river has changed significantly within the regulated reaches, reflecting the demand of consumers, with approximately $58 \%$ of mean natural annual flow, or $25.8 \mathrm{GL} /$ year (Melbourne Water 2005), now taken from the catchment for irrigation (64\%), urban (28\%) and other uses $(8 \%)$.

The Werribee river condition is rated as 'Good' in the upper catchment and through the Rowsley Fault by Melbourne Water (2007), since significant sections are protected as State parks. This means that the riparian vegetation is native and diverse. In the plains, both the upper basalt floodplain (before the Rowsley fault), and the floodplain around Werribee, the river condition is considered 'Moderate to Poor'. This is due to the change in the surrounding environment through the predominate presence of exotic flora and river flow regulation. To mitigate the effect of rapid urban development, considerable improvement in the quality of water draining from urban developments is being achieved through the creation of temporary storage areas, e.g. urban forests, and integrating stormwater treatment into the landscape; e.g. wetlands. However, one of the most significant concerns is blooms of potential toxic blue-green algae (Cottingham et al. 1997). This concern has arisen because of the significant agricultural and urban run-offs into the river system in this area. To date, the limited monitoring that has been undertaken at some locations has observed high nitrogen and phosphorous levels, 27 and $1.4 \mathrm{mg} / \mathrm{L}$, respectively. However, this is partly due to the naturally high nitrogen levels of the river (EPA Victoria 2000). Unfortunately, water monitoring on the Werribee river has been severely limited. Thus, SSF Australia is undertaking a detailed water monitoring program in conjunction with the local Werribee Riverkeepers group. The program is currently monitoring the monthly condition of the Werribee river at 13 sites for standard parameters of temperature, flow, $\mathrm{pH}$, conductivity, turbidity, ammonia, nitrate, phosphate, chlorine and macro invertebrates count. 
The goal of the project is that after completion of the initial year long water quality survey members of the local Werribee Riverkeepers will be taught the necessary skills to undertake water monitoring independently. This will allow them to rapidly monitor any changes in the river conditions and thus locate sources of deterioration in river quality. With this knowledge, the community group can then focus on rehabilitation efforts on specifically identified sections of the river. Two sections have already been tentatively identified as requiring urgent rehabilitation assistance. Specifically, where the river leaves the Werribee township and around Cottrell street ford which is in grazing land. Both of these regions, due to low flows, have been invaded by exotic flora, experience high algal levels and have residual damage from past pollution.

Human impact on the Moonee Ponds Creek and Werribee River since European settlement has significantly altered their conditions. The clearing of large sections of the catchments and subsequent use of land for agriculture and urbanisation has resulted in widespread erosion, increased nutrient levels and loss of habitat for aquatic life. Despite widespread prob- lems, both water systems can be returned to a state that more closely resembles their original condition, through local community efforts in protecting and improving the environment, conditions can be achieved with minimal negative impacts on the viability of surrounding economies.

\section{References}

ABS, (2008). Regional population growth, Australian Bureau of Statistics publication, No. 3218.0.

Cottingham, P., Jeffrey, G., \& Schalken, T. (1997). Draft water quality strategy for the Werribee river basin. EPA publication.

EPA Victoria, (2000). The health of streams in the Werribee catchment. EPA publication, No. 698.

EPA Victoria, (2007). Drought and river health in Victoria. EPA publication, No. 1171.

Melbourne Water (2005). The environmental water needs of the Werribee river: Final report-flow recommendations, Melbourne Water publication, No. BN001-3D.

Melbourne Water (2006). Annual water quality fact sheets for Melbourne Water water quality long term monitoring sites. Melbourne Water publication.

Melbourne Water, (2007). Port Phillip and Westernport regional river health strategy. Melbourne Water publication, ISBN 0975189999. 